\title{
New Isolated Single-Phase AC-DC Converter for Universal Input Voltage
}

\author{
Ming-Rong Lee*, Lung-Sheng Yang ${ }^{\dagger}$, and Chia-Ching Lin ${ }^{*}$ \\ ${ }^{*}$ Dept. of Electrical Engineering, Far East University, Tainan City, Taiwan
}

\begin{abstract}
This paper investigates a new isolated single-phase AC-DC converter, which integrates a modified AC-DC buck-boost converter with a DC-DC forward converter. The front semi-stage is operated in discontinuous conduction mode (DCM) to achieve an almost unity power factor and a low total harmonic distortion of the input current. The rear semi-stage is used for step-down voltage conversion and electrical isolation. The front semi-stage uses a coupled inductor with the same winding-turn in the primary and secondary sides, which is charged in series during the switch-on period and is discharged in parallel during the switch-off period. The discharging time can be shortened. In other words, the duty ratio can be extended. This semi-stage can be operated in a larger duty-ratio range than the conventional AC-DC buck-boost converter for DCM operation. Therefore, the proposed converter is suitable for universal input voltage $\left(90 \sim 264 \mathrm{~V}_{\mathrm{rms}}\right)$ and a wide output-power range. Moreover, the voltage stress on the DC-link capacitor is low. Finally, a prototype circuit is implemented to verify the performance of the proposed converter.
\end{abstract}

Key words: Power factor correction, Discontinuous conduction mode, Universal input voltage

\section{INTRODUCTION}

Since DC power sources are widely used in many applications, including DC power supplies, battery chargers, and lighting systems, AC-DC power conversion plays an important role. Traditionally, the diode bridge rectifier is used for AC-DC power conversion. This rectifier has the advantages of a simple circuit configuration and a low cost. Nevertheless, this rectifier results in some power pollutions, such as a high pulsating input current, a low power factor, and a high total harmonic distortion of the input current $\left(\mathrm{THD}_{\mathrm{i}}\right)$. In order to improve these power pollutions and to meet the requirements set by international regulatory standards, such as the international electrotechnical commission (IEC) and IEEE-519, power factor correction (PFC) topologies have been investigated [1]-[7]. These PFC circuits are used to cascade a DC-DC converter for DC power-supply applications. They can be divided into two approaches, two stages and single stage approaches. The two-stage structure can achieve a near unity power factor and

Manuscript received Dec. 29, 2012; revised Mar. 20, 2013.

Recommended for publication by Associate Editor Sangshin Kwak.

†Corresponding Author: yanglungsheng@yahoo.com.tw

Tel: +886-6-5979566-5410, Far East University

Dept. of Electrical Engineering, Far East University, Tainan City, Taiwan a low $\mathrm{THD}_{\mathrm{i}}$. However, it suffers from the problems of high cost and a complicated control [8], [9]. Therefore, the single-stage PFC topologies have been studies to achieve good power quality and low cost in low power applications. Some single-stage structures use the boost converter in the front semi-stage, which operates in discontinuous conduction mode (DCM), to achieve a good power quality [10]-[12]. Nevertheless, the DC-link voltage of this single-stage converter is higher than the amplitude of the input voltage. Thus the DC-link voltage will be higher than $450 \mathrm{~V}$ at the universal input voltage $\left(90 \sim 264 \mathrm{~V}_{\mathrm{rms}}\right)$. Some topologies have been studied to reduce the DC-link voltage [13]-[16]. However, they result in a poor $\mathrm{THD}_{\mathrm{i}}$. A buck-boost converter with DCM operation is utilized in the front semi-stage of the single-stage structures to provide good power quality and a low DC-link voltage [17]-[20]. However, these converters do not provide electrical isolation [17], [18]. In [19] and [20], the leakage-inductor energy of the transformer can not be recycled.

A new isolated single-phase AC-DC converter is presented in this paper, as shown in Fig. 1. The proposed converter integrates a modified AC-DC buck-boost converter with a DC-DC forward converter. The transformer can provide electrical isolation. The tertiary winding $N_{3}$ is used for recycling the residual magnetism of the transformer to the 


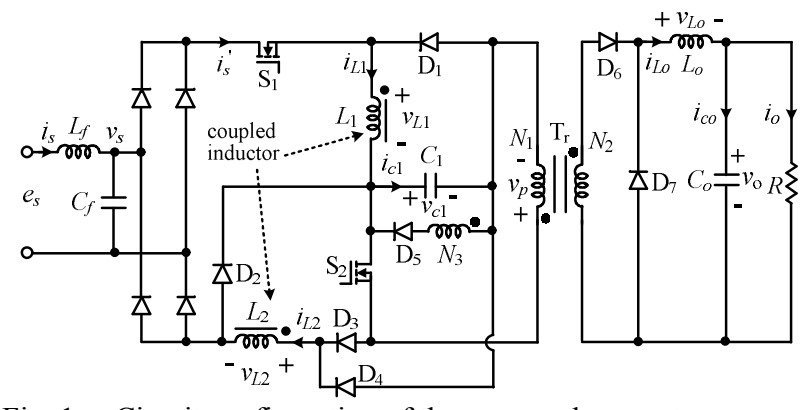

Fig. 1. Circuit configuration of the proposed converter.

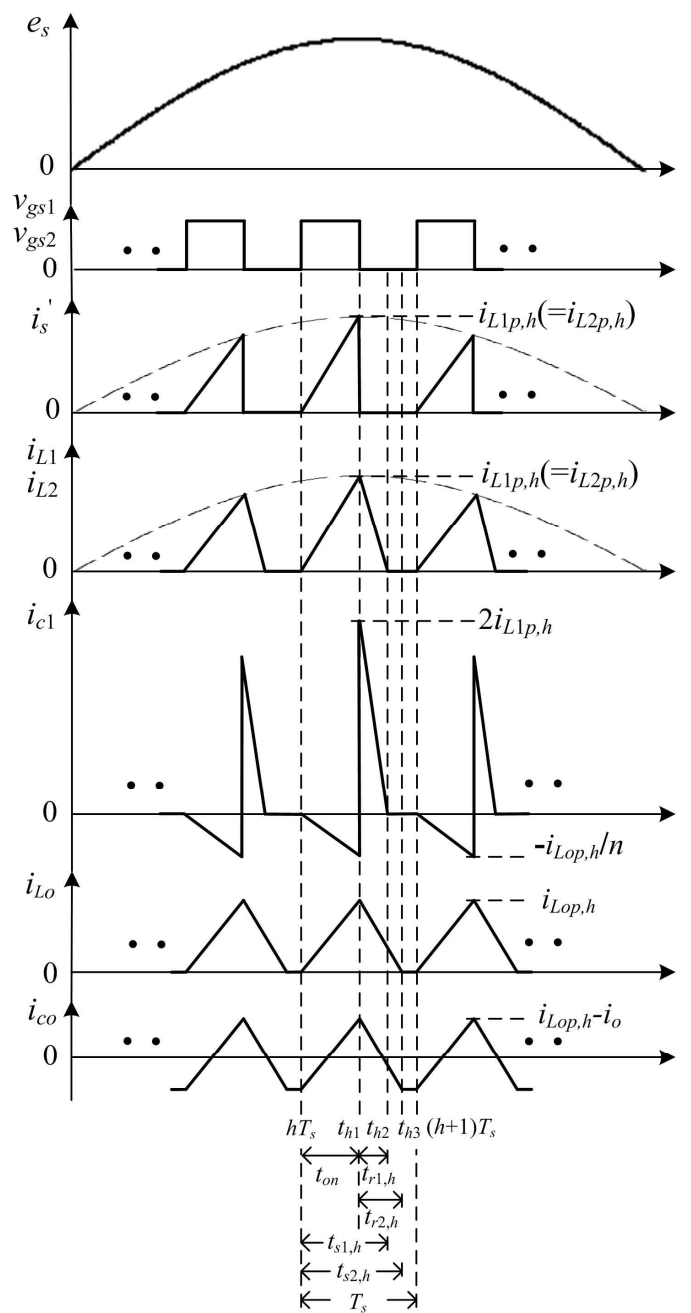

Fig. 2. Key waveforms of the proposed converter for $0<\omega t<\pi$.

capacitor $C_{1}$. The turns of the tertiary winding $N_{3}$ are equal the turns of the primary winding $N_{1}$. This converter can achieve a high power factor, a low $\mathrm{THD}_{i}$, and a low DC-link voltage. In addition, it can be used for universal input voltage.

\section{OPERATING PRINCIPLE}

The two semi-stages of the proposed converter are operated in DCM with a fixed duty ratio by using a simple pulse-width modulation control strategy. The switches, $\mathrm{S}_{1}$ and $\mathrm{S}_{2}$, are triggered using the same control signal. A coupled inductor with same winding-turn in the primary and secondary sides is employed in the proposed converter. The primary and secondary windings of the coupled inductor are charged in series from the line source during the switch-on period and are discharged in parallel during the switch-off period. The discharge time can be shortened. The duty ratio can be extended. Thus the front semi-stage can be operated in a larger duty-ratio range than the conventional AC-DC buck-boost converter for DCM operation. Therefore, the proposed converter can be applied for universal input voltage and a wide output-power range. Fig. 2 shows some key waveforms in a half line source period. Due to the symmetrical characteristics of the single-phase system, the following operating principle is analyzed for $0<\omega t<\pi$, where $\omega$ is the line angular frequency.

(I) Mode 1: The current-flow path is shown in Fig. 3(a). When the switches, $S_{1}$ and $S_{2}$, are turned on during time interval $\left[h T_{s}, t_{h 1}\right]$, the primary and secondary windings of the coupled inductor are charged by series from the line source, and the energy stored in DC-link capacitor $C_{1}$ is discharged to output inductor $L_{o}$, output capacitor $C_{o}$, and the load via transformer $\mathrm{T}_{\mathrm{r}}$. The voltage $v_{p}$ across the primary winding of the transformer is equal to $v_{c 1}$.

(II) Mode 2: The current-flow path is shown in Fig. 3(b). While the switches, $S_{1}$ and $S_{2}$, are turned off during time interval $\left[t_{h 1}, t_{h 2}\right]$, the primary and secondary windings of the coupled inductor release their energies by parallel to DC-link capacitor $C_{1}$, and the energy stored in output inductor $L_{o}$ is released to output capacitor $C_{o}$ and the load. The residual magnetism of the transformer is recycled to capacitor $C_{1}$ via tertiary winding $N_{3}$. The voltage $v_{p}$ across the primary winding of the transformer is equal to $-v_{c 1}$.

(III) Mode 3: The current-flow path is shown in Fig. 3(c). The switches, $S_{1}$ and $S_{2}$, are still turned off during time interval $\left[t_{h 2}, t_{h 3}\right]$. The coupled-inductor currents, $i_{L 1}$ and $i_{L 2}$, are equal to zero at $t=t_{h 2}$. The energy stored in output inductor $L_{o}$ is still transferred to capacitor $C_{o}$ and the load.

(IV) Mode 4: The current-flow path is shown in Fig. 3(d). While $S_{1}$ and $S_{2}$ are still turned off during time interval $\left[t_{h 3}\right.$, $(h+1) T_{s}$ ], the energy stored in output inductor $L_{o}$ is released to empty at $t=t_{h 3}$. The load is supplied from capacitor $C_{o}$.

\section{STEADY-STATE ANALYSIS}

Due to the symmetrical characteristics of single-phase systems, the following analysis is discussed for $0<\omega t<\pi$. For the sake of simplicity, the effect of the input filter is neglected. The line voltage is given as:

$$
e_{s}(t)=v_{s}(t)=\sqrt{2} V_{r m s} \sin \omega t=V_{m} \sin \omega t
$$

where $V_{r m s}$ and $V_{m}$ are the root-mean-square value and the amplitude of the line voltage. 


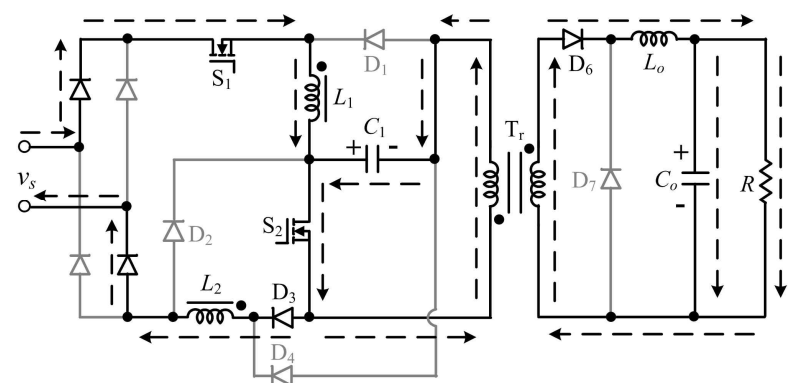

(a) Mode 1 .

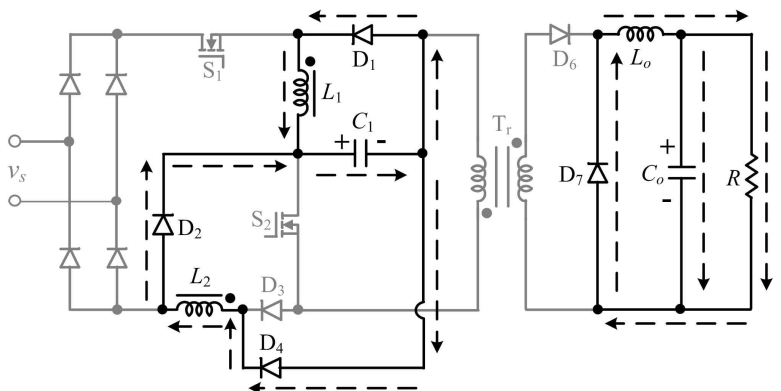

(b) Mode 2.

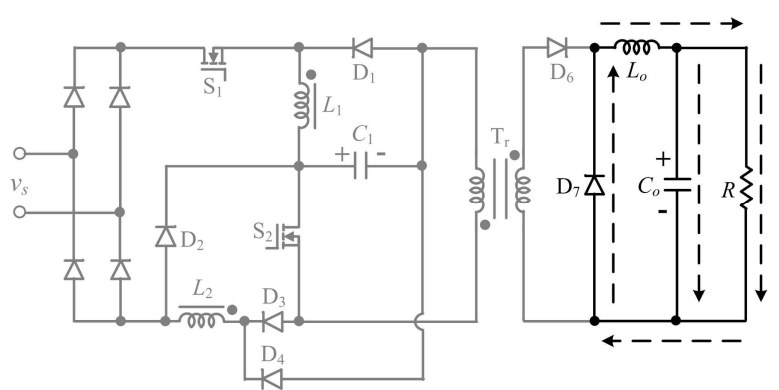

(c) Mode 3 .

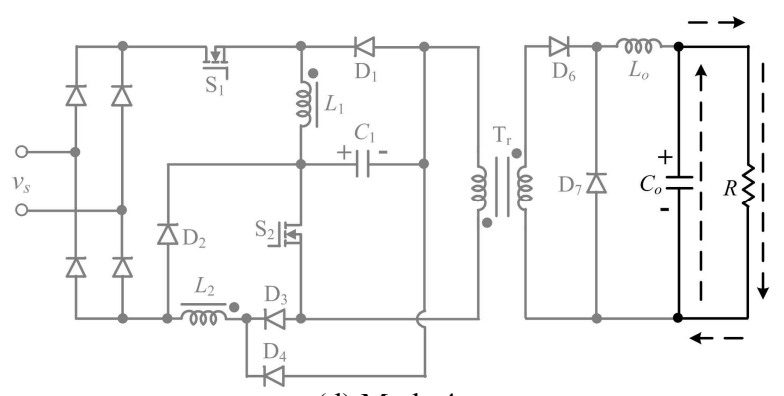

(d) Mode 4

Fig. 3. Current-flow path of the proposed converter for $0<\omega t<\pi$.

Some of the parameters, such as $t_{o n}, t_{h 1}, t_{h 2}, t_{h 3}, t_{r 1, h}, t_{r 2, h}$, $t_{s 1, h}$, and $t_{s 2, h}$, are used for the following steady-state analyses. These parameters are defined in Fig. 2. Since the switching frequency $f_{s}$ is much larger than the line frequency $f_{1}$, the line voltage can be considered as a piecewise constant during each switching period. Assuming that $m$ is the switching number within time interval $[0, \pi / \omega], m$ is equal to $f_{s} / 2 f_{1}$. The following analysis is considered during switching period $\left[h T_{s}\right.$, $\left.(h+1) T_{s}\right]$, where $h=0,1, \ldots ., m-1$. Since the primary and secondary winding turns of the coupled inductor are the same, the inductance of the coupled inductor in the primary and secondary sides are expressed as:

$$
L_{1}=L_{2}=L
$$

The mutual inductance $M$ of the coupled inductor is given by

$$
M=k \sqrt{L_{1} L_{2}}=k L
$$

where $k$ is the coupling coefficient of the coupled inductor.

The voltages across the primary and secondary windings of the coupled inductor are as follows:

$$
\begin{aligned}
& v_{L 1}=L_{1} \frac{d i_{L 1}}{d t}+M \frac{d i_{L 2}}{d t}=L \frac{d i_{L 1}}{d t}+k L \frac{d i_{L 2}}{d t} \\
& v_{L 2}=M \frac{d i_{L 1}}{d t}+L_{2} \frac{d i_{L 2}}{d t}=k L \frac{d i_{L 1}}{d t}+L \frac{d i_{L 2}}{d t}
\end{aligned}
$$

When $S_{1}$ and $S_{2}$ are turned on, the following equations are obtained as:

$$
\begin{gathered}
i_{L 1}=i_{L 2}, \quad h T_{s} \leq t \leq t_{h 1} \\
v_{L 1}+v_{L 2}=\left|e_{s}\left(t_{h}\right)\right|, \quad h T_{s} \leq t \leq t_{h 1} \\
\frac{v_{c 1}}{n}=v_{L o}+v_{o}=L_{o} \frac{d i_{L o}(t)}{d t}+v_{o}, \quad h T_{s} \leq t \leq t_{h 1}
\end{gathered}
$$

where $n$ is the turns ratio $\left(N_{1} / N_{2}\right)$ of transformer Tr.

Substituting (4)-(6) into (7), yields:

$$
\frac{d i_{L 1}(t)}{d t}=\frac{d i_{L 2}(t)}{d t}=\frac{\left|e_{s}\left(t_{h}\right)\right|}{2(1+k) L}, \quad h T_{s} \leq t \leq t_{h 1}
$$

The coupled-inductor currents, $i_{L 1}$ and $i_{L 2}$, are derived as:

$$
i_{L 1}(t)=i_{L 2}(t)=\frac{\left|e_{s}\left(t_{h}\right)\right|}{2(1+k) L}\left(t-h T_{s}\right), \quad h T_{s} \leq t \leq t_{h 1}
$$

From (8), the following equation is found to be:

$$
\frac{d i_{L o}(t)}{d t}=\frac{1}{L_{o}}\left(\frac{v_{c 1}}{n}-v_{o}\right), \quad h T_{s} \leq t \leq t_{h 1}
$$

At $t=t_{h 1}$, the peak values of $i_{L 1}, i_{L 2}$, and $i_{L o}$ are given by:

$$
\begin{gathered}
i_{L 1 p, h}=i_{L 2 p, h}=\frac{\left|e_{s}\left(t_{h}\right)\right|}{2(1+k) L} t_{o n} \\
i_{L o p, h}=\frac{1}{L_{o}}\left(\frac{v_{c 1}}{n}-v_{o}\right) t_{o n}
\end{gathered}
$$

where $t_{o n}$ is equal to $d T_{s}$ and $d$ is the duty ratio.

While $S_{1}$ and $S_{2}$ are turned off, the voltages across the primary and secondary windings of the coupled inductor are obtained as:

$$
\begin{aligned}
& v_{L 1}=v_{L 2}=-v_{c 1}, \quad t_{h 1} \leq t \leq t_{h 2} \\
& v_{L o}=-v_{o}, \quad t_{h 1} \leq t \leq t_{h 3}
\end{aligned}
$$

Substituting (4) and (5) into (14), yields:

$$
\frac{d i_{L 1}(t)}{d t}=\frac{d i_{L 2}(t)}{d t}=-\frac{v_{c 1}}{(1+k) L}, \quad t_{h 1} \leq t \leq t_{h 2}
$$

Therefore, $i_{L 1}$ and $i_{L 2}$ are found to be:

$i_{L 1}(t)=i_{L 2}(t)=-\frac{v_{c 1}}{(1+k) L}\left(t-t_{h 1}\right)+i_{L 1 p, h}, \quad t_{h 1} \leq t \leq t_{h 2}$

From (15), the following equation is derived as:

$$
\frac{d i_{L o}}{d t}=-\frac{v_{o}}{L_{o}}, \quad t_{h 1} \leq t \leq t_{h 3}
$$


Thus:

$$
i_{\text {Lo }}(t)=-\frac{v_{o}}{L_{o}}\left(t-t_{h 1}\right)+i_{\text {Lop }, h}, \quad t_{h 1} \leq t \leq t_{h 3}
$$

Since $i_{L 1}\left(t_{h 2}\right)=i_{L 2}\left(t_{h 2}\right)=0$ and $i_{L o}\left(t_{h 3}\right)=0$, the peak values of $i_{L 1}, i_{L 2}$, and $i_{L o}$ are obtained from (17) and (19).

$$
\begin{aligned}
i_{L 1 p, h}=i_{L 2 p, h} & =\frac{v_{c 1}}{(1+k) L} t_{r 1, h} \\
i_{L o p, h} & =\frac{v_{o}}{L_{o}} t_{r 2, h}
\end{aligned}
$$

where $t_{r 1, h}=t_{h 2}-t_{h 1}$ and $t_{r 2, h}=t_{h 3}-t_{h 1}$.

From (12), (13), (20), and (21), the time durations, $t_{r 1, h}$ and $t_{r 2, h}$, are obtained as follows:

$$
\begin{gathered}
t_{r 1, h}=\frac{\left|e_{s}\left(t_{h}\right)\right|}{2 v_{c 1}} d T_{s} \\
t_{r 2, h}=\frac{1}{v_{o}}\left(\frac{v_{c 1}}{n}-v_{o}\right) d T_{s}
\end{gathered}
$$

\section{A. Unfiltered Input Current $i_{s}$}

From Fig. 2, the average unfiltered input current $i_{s}$ in one switching period $T_{s}$ can be derived as:

$$
i_{s, \text { avg }}^{\prime}(t)=\frac{t_{\text {on }} i_{L 1 p}}{2 T_{s}}=\frac{d^{2} T_{s} V_{m}}{4(1+k) L}|\sin \omega t|
$$

Equation (24) indicates that the average unfiltered input current is sinusoidal and is in phase with the input voltage. Moreover, the harmonic components of $i_{s}$ are distributed over multiples of the switching frequency. Thus it is very easy to filter out the harmonic components by employing a set of input filters $L_{f}-C_{f}$. The cutoff frequency of the input filter is much lower than the switching frequency. The cutoff frequency of the input filter is determined to be:

$$
f_{c}=\frac{1}{2 \pi \sqrt{L_{f} C_{f}}}
$$

\section{B. Voltage Gain}

From Fig. 2, the average values of $i_{c 1}$ and $i_{c o}$ during time interval $\left[h T_{s},(h+1) T_{s}\right]$ can be computed as:

$$
\begin{gathered}
i_{c 1, h}=\frac{1}{T_{s}}\left(i_{L 1 p, h} t_{r 1, h}-\frac{i_{L o p, h}}{2 n} t_{o n}\right) \\
i_{c o, h}=\frac{1}{T_{s}}\left[\frac{1}{2} i_{L o p, h}\left(t_{o n}+t_{r 2, h}\right)-i_{o} T_{s}\right]
\end{gathered}
$$

Substituting (1), (12), (13), (22), and (23) into (26) and (27) yields:

$$
\begin{gathered}
i_{c 1, h}=\frac{d^{2} T_{s} V_{m}^{2}}{4(1+k) L v_{c 1}} \sin ^{2} \omega t_{h}-\frac{d^{2} T_{s}\left(v_{c 1}-n v_{o}\right)}{2 n^{2} L_{o}} \\
i_{c o, h}=\frac{d^{2} T_{s} v_{c 1}\left(v_{c 1}-n v_{o}\right)}{2 n^{2} L_{o} v_{o}}-i_{o}
\end{gathered}
$$

Thus the average value of $i_{c 1}$ during one half of line-source period $[0, \pi / \omega]$, is written as follows:

$$
\begin{aligned}
i_{c 1, a v g} & =\frac{\omega}{\pi} \sum_{h=0}^{m-1} i_{c 1, h} T_{s} \\
& =\frac{\omega}{\pi} \sum_{h=0}^{m-1}\left[\frac{d^{2} T_{s} V_{m}^{2}}{4(1+k) L v_{c 1}} \sin ^{2} \omega t_{h}-\frac{d^{2} T_{s}\left(v_{c 1}-n v_{o}\right)}{2 n^{2} L_{o}}\right] T_{s}
\end{aligned}
$$

Due to the fact that $m>1$, the above equation can be approximated as:

$$
\begin{aligned}
i_{c 1, a v g} & =\frac{\omega}{\pi} \int_{0}^{\frac{\pi}{\omega}}\left[\frac{d^{2} T_{s} V_{m}^{2}}{4(1+k) L v_{c 1}} \sin ^{2} \omega t-\frac{d^{2} T_{s}\left(v_{c 1}-n v_{o}\right)}{2 n^{2} L_{o}}\right] d t \\
& =\frac{d^{2} T_{s} V_{m}^{2}}{8(1+k) L v_{c 1}}-\frac{d^{2} T_{s}\left(v_{c 1}-n v_{o}\right)}{2 n^{2} L_{o}}
\end{aligned}
$$

Then, the differential equation of $v_{c 1}$ is given by:

$$
\frac{d v_{c 1}}{d t}=\frac{d^{2} T_{\mathrm{s}}}{2 C_{1}}\left[\frac{V_{m}^{2}}{4(1+k) L v_{c 1}}-\frac{v_{c 1}-n v_{o}}{n^{2} L_{o}}\right]
$$

From (29), the differential equation of $v_{o}$ during one switching period is obtained as follows:

$$
\frac{d v_{o}}{d t}=\frac{1}{C_{o}}\left[\frac{d^{2} T_{s} v_{c 1}\left(v_{c 1}-n v_{o}\right)}{2 n^{2} L_{o} v_{o}}-\frac{v_{o}}{R}\right]
$$

Thus the following equations of the DC model can be derived from (32) and (33).

$$
\begin{aligned}
& \frac{V_{m}^{2}}{4(1+k) L V_{c 1}}=\frac{V_{c 1}-n V_{o}}{n^{2} L_{o}} \\
& \frac{D^{2} T_{s} V_{c 1}\left(V_{c 1}-n V_{o}\right)}{2 n^{2} L_{o} V_{o}}=\frac{V_{o}}{R}
\end{aligned}
$$

where $V_{c 1}, V_{o}$, and $D$ are the DC quantities of $v_{c 1}, v_{o}$, and $d$, respectively.

The normalized inductor time constant of the two semi-stages are defined as follows:

$$
\begin{gathered}
\tau_{L} \equiv \frac{L}{R T_{s}}=\frac{L f_{s}}{R} \\
\tau_{L o} \equiv \frac{L_{o}}{R T_{s}}=\frac{L_{o} f_{s}}{R}
\end{gathered}
$$

where $f_{s}$ is the switching frequency.

By substituting (36) and (37) into (34) and (35), the voltage gain of the proposed converter is found to be:

$$
\begin{gathered}
G=\frac{V_{o}}{V_{m}}=G_{1} G_{2} \\
\text { where } G_{1}=\frac{V_{c 1}}{V_{m}}=\sqrt{\frac{n^{2} \tau_{L o}}{4(1+k) \tau_{L}\left(1-n G_{2}\right)}} \\
G_{2}=\frac{V_{o}}{V_{c 1}}=\frac{-D^{2}+\sqrt{D^{4}+8 D^{2} \tau_{L o}}}{4 n \tau_{L o}}
\end{gathered}
$$

\section{Boundary Operating Condition}

In order to ensure that the two semi-stages of the proposed converter are operated in DCM, $i_{L 1}, i_{L 2}$, and $i_{L o}$ must go to zero during the switch-off period in each switching period. From Fig. 2, the two time durations, $t_{s 1, h}$ and $t_{s 2, h}$, are obtained as follows: 


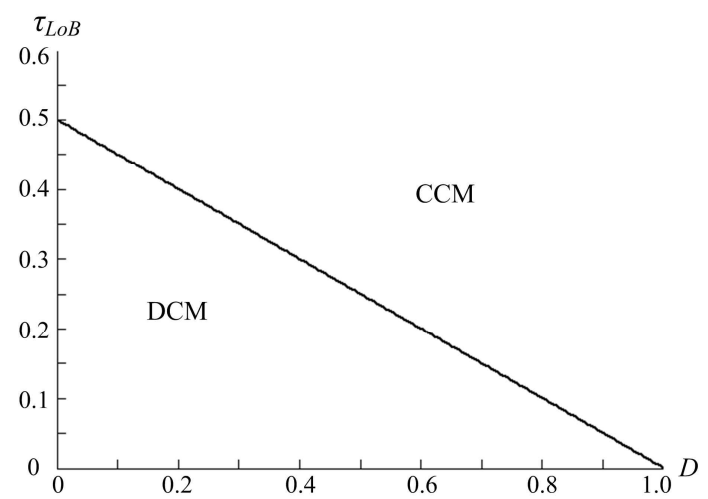

(a)

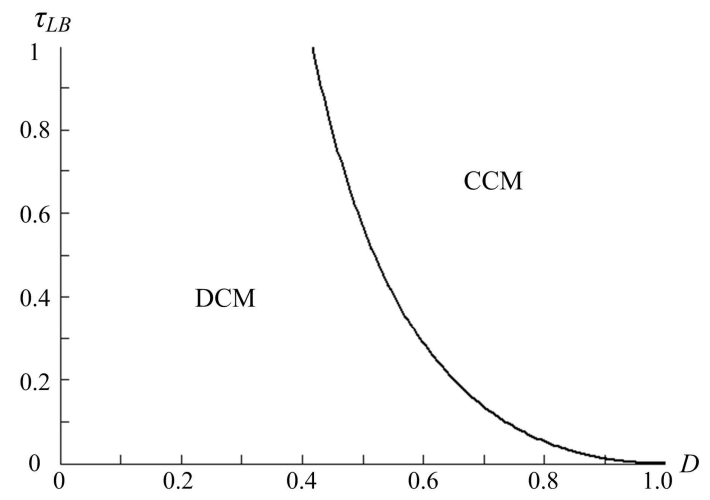

(b)

Fig. 4. Boundary condition. (a) Rear semi-stage; (b) Front semi-stage (under $\tau_{L o}=0.25, k=1$, and $n=1.5$ ).

$$
\begin{gathered}
t_{s 1, h}=t_{o n}+t_{r 1, h}=\frac{D T_{s}\left(2 V_{c 1}+\left|e_{s}\left(t_{h}\right)\right|\right)}{2 V_{c 1}} \\
t_{s 2, h}=t_{o n}+t_{r 2, h}=\frac{V_{c 1} D T_{s}}{n V_{o}}
\end{gathered}
$$

When the maximum of $t_{s 1, h}$ is equal to $T_{s}$ and $\left|e_{s}\left(t_{h}\right)\right|$ is equal to $V_{m}$, the front semi-stage of the proposed converter is operated in boundary conduction mode (BCM). Similarly, when $t_{s 2, h}$ is equal to $T_{s}$, the rear semi-stage of the proposed converter is also operated in BCM. Thus by simplifying (41) and (42), the boundary voltage gains are found to be:

$$
\begin{gathered}
G_{1, b c}=\frac{V_{c 1}}{V_{m}}=\frac{D}{2(1-D)} \\
G_{2, b c}=\frac{V_{o}}{V_{c 1}}=\frac{D}{n} \\
G_{b c}=G_{1, b c} G_{2, b c}=\frac{D^{2}}{2 n(1-D)}
\end{gathered}
$$

When $G_{1}=G_{1, b c}$ and $G_{2}=G_{2, b c}$, the normalized inductor time constants in BCM are given by:

$$
\begin{gathered}
\tau_{L o B}=\frac{1-D}{2} \\
\tau_{L B}=\frac{4 n^{2} \tau_{L o}^{2}(1-D)^{2}}{(1+k) D^{2}\left(4 \tau_{L o}+D^{2}-\sqrt{D^{4}+8 D^{2} \tau_{L o}}\right)}
\end{gathered}
$$

From (46) and (47), the curve of $\tau_{L o B}$ is plotted in Fig. 4(a). It can be seen that the rear semi-stage of the proposed converter is operated in DCM if $\tau_{L o}<\tau_{L o B}$. Assuming that $\tau_{L o}=0.25, k=1$, and $n=1.5$, the curve of $\tau_{L B}$ is plotted in Fig. 4(b). It can be seen that the front semi-stage of the proposed converter is operated in DCM if $\tau_{L}<\tau_{L B}$.

\section{SELECTIONS OF INDUCTORS AND CAPACITORS}

A. Selection of Inductors $L_{1}, L_{2}$, and $L_{o}$

In order to ensure that the two semi-stages of the proposed converter are operated in DCM, appropriate $\tau_{L O B}$ and $\tau_{L B}$ are selected under the required voltage gain. Thus $L_{o}, L_{1}$, and $L_{2}$ must satisfy the following inequality.

$$
\begin{gathered}
L_{o}<\frac{R}{f_{s}} \tau_{L o B} \\
L_{1}=L_{2}=L<\frac{R}{f_{s}} \tau_{L B}
\end{gathered}
$$

\section{B. Selection of DC-Link Capacitor $C_{1}$}

From (28), the average value of the current $i_{c 1, h}$ per switching period can be rewritten as:

$$
i_{c 1, h}=\frac{D^{2} T_{s}}{2}\left[\frac{V_{m}^{2}}{4(1+k) L V_{c 1}}-\frac{V_{c 1}-n V_{o}}{n^{2} L_{o}}\right]-\frac{D^{2} T_{s} V_{m}^{2}}{8(1+k) L V_{c 1}} \cos 2 \omega t_{h}
$$

Substituting (34) into (50), the ripple of the DC-link voltage per switching period is obtained as:

$$
\Delta V_{c 1, h}=\left[-\frac{D^{2} V_{m}^{2}}{8(1+k) L C_{1} f_{s} V_{c 1}} \cos 2 \omega t_{h}\right] T_{s}
$$

Hence, the function of the ripple of the DC-link voltage per one half line-source period can be computed as:

$$
\begin{aligned}
\Delta V_{c 1}(t) & =\int_{0}^{t}\left[-\frac{D^{2} V_{m}^{2}}{8(1+k) L C_{1} f_{s} V_{c 1}} \cos 2 \omega t^{\prime}\right] d t^{\prime} \\
& =-\frac{D^{2} V_{m}^{2}}{8(1+k) L C_{1} f_{s} V_{c 1}} \times \frac{\sin 2 \omega t}{2 \omega}
\end{aligned}
$$

From (52), the ripple of the DC-link voltage per one half line-source period is derived as:

$$
V_{c 1, \text { ripple }}=2\left|\Delta V_{c 1}(t)\right|_{\text {peak }}=\frac{D^{2} V_{m}^{2}}{8(1+k) \omega L C_{1} f_{s} V_{c 1}}
$$

Thus:

$$
\frac{V_{c 1, \text { ripple }}}{V_{c 1}}=\frac{D^{2} V_{m}^{2}}{8(1+k) \omega L C_{1} f_{s} V_{c 1}^{2}}=\frac{D^{2}}{8(1+k) \omega L C_{1} f_{s} G_{1}^{2}}
$$

Therefore, to satisfy the specification of the ripple percentage of the DC-link voltage, capacitor $C_{1}$ needs to satisfy the following inequality:

$$
C_{1} \geq \frac{D^{2}}{8(1+k) \omega L f_{s} G_{1}^{2}} \times \frac{V_{c 1}}{V_{c 1, \text { ripple }}}
$$

\section{EXPERIMENTAL RESULTS}

In order to verify the feasibility of the proposed converter, a prototype circuit has been implemented in the laboratory. 


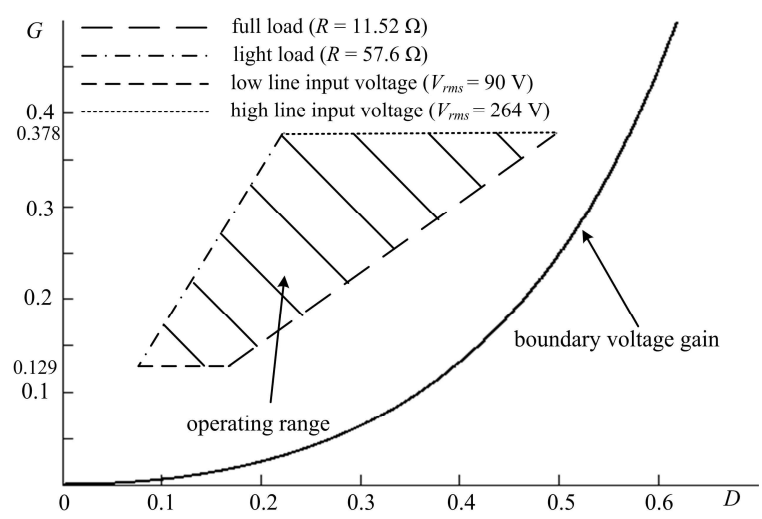

Fig. 5. Operating range of the prototype circuit.

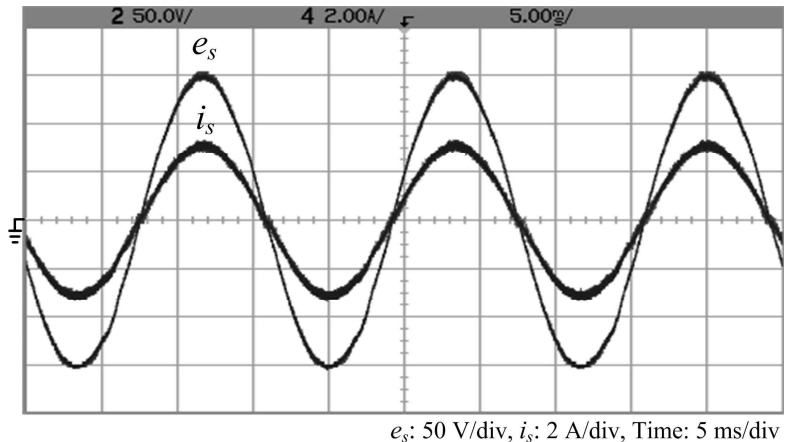

Fig. 6. Waveforms of input voltage and input current.

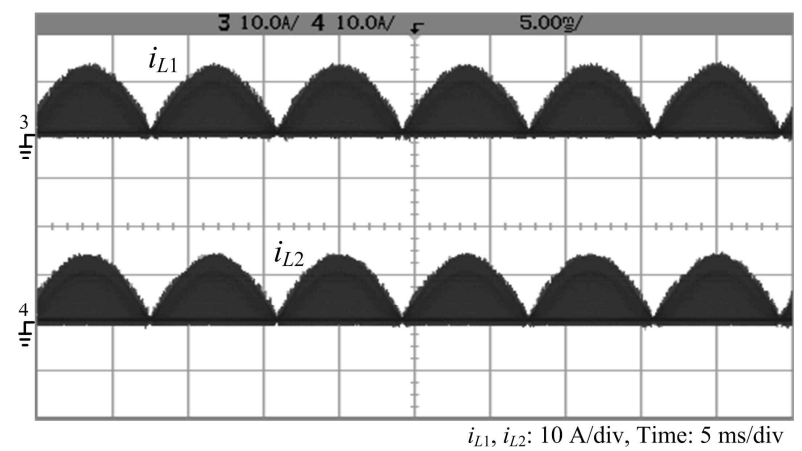

Fig. 7. Waveforms of coupled-inductor currents.

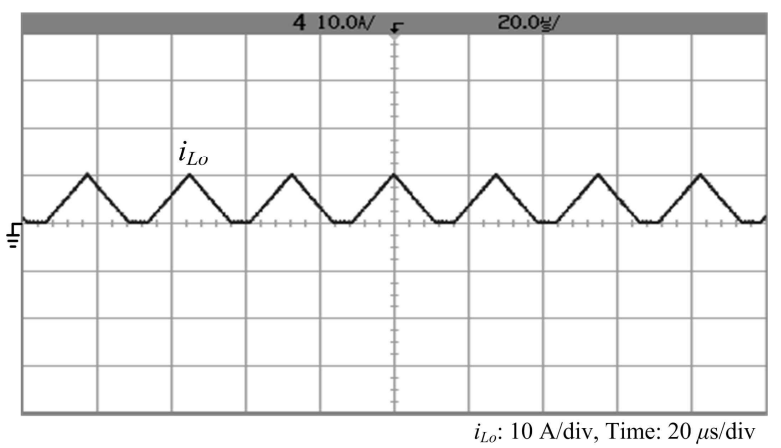

Fig. 8. Waveform of output-inductor current.

The electrical specifications and circuit parameters are selected to be $V_{r m s}=90 \sim 264 \mathrm{~V}\left(V_{m}=127 \sim 373 \mathrm{~V}\right), V_{o}=48 \mathrm{~V}$, $P_{o}=40 \sim 200 \mathrm{~W}(R=11.52 \sim 57.6 \Omega), f_{1}=60 \mathrm{~Hz}, f_{s}=36 \mathrm{kHz}$,

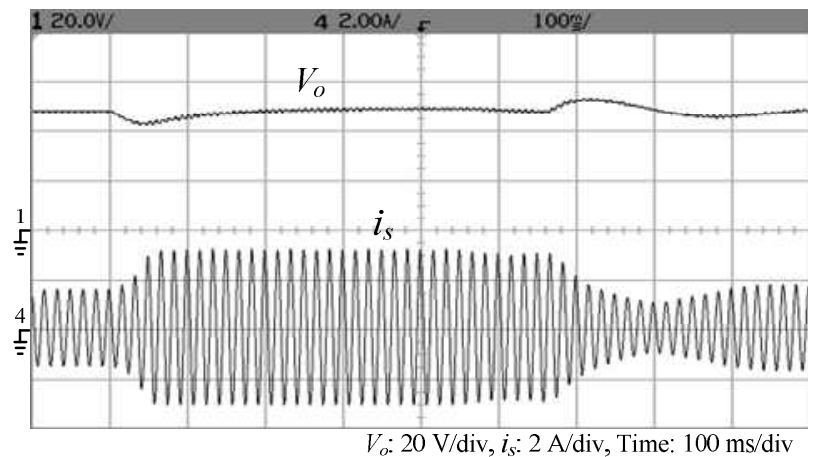

Fig. 9. Waveforms of output voltage $V_{o}$ and input current $i_{s}$ under load variation between $100 \mathrm{~W}$ and $200 \mathrm{~W}$.

$L_{f}=1.5 \mathrm{mH}, C_{f}=600 \mathrm{nF}$, and $n=1$. From the electrical specifications, it can be seen that the voltage gain $G$ is varied from 0.129 to 0.378 . By substituting $G=0.378$ and $n=1$ into (45), the maximum duty ratio $D_{\max }$ is derived as 0.57 . By substituting $D_{\max }=0.57$ into (46), $\tau_{L O B}$ is found to be 0.215 . By substituting $D_{\max }=0.57, \tau_{L O}=0.215, n=1$, and $k=1$ into (47), $\tau_{L B}$ is given as 0.142 . By using (48) and (49), inductors, $L_{1}, L_{2}$, and $L_{o}$, are obtained as follows:

$$
\begin{gathered}
L_{o}<\frac{R}{f_{s}} \tau_{L o B}=\frac{11.52}{36 \mathrm{k}} \times 0.215=68.8 \mu \mathrm{H} \\
L<\frac{R}{f_{s}} \tau_{L B}=\frac{11.52}{36 \mathrm{k}} \times 0.142=45.4 \mu \mathrm{H}
\end{gathered}
$$

Due to the fact that $L_{1}=L_{2}=L, L_{1}$ and $L_{2}$ are chosen to be $34.1 \mu \mathrm{H}$. In addition, $L_{o}$ is selected to be $54.6 \mu \mathrm{H}$. Thus $\tau_{L O}$ and $\tau_{L}$ are 0.171 and 0.107 under the full-load condition $(R=$ $11.52 \Omega$ ), and $\tau_{L O}$ and $\tau_{L}$ are 0.0341 and 0.0213 under the light-load condition ( $R=57.6 \Omega$ ). By substituting $k=1, n=1$, and the above values of $\tau_{L o}$ and $\tau_{L}$ into (38), the operating range of the prototype circuit is shown in Fig. 5. It can be seen that that the proposed converter is operated in DCM. The ripple percentage of DC-link voltage $V_{c 1}$ is considered under the conditions $V_{r m s}=90 \mathrm{~V}$ and $R=11.52 \Omega$. Thus by substituting $G=0.378, \tau_{L O}=0.171, \tau_{L}=0.107, n=1$, and $k=$ 1 into (38), the duty ratio $D$ is derived as 0.5 . From (39) and (40), $G_{2}$ and $G_{1}$ are found to be 0.564 and 0.677 , respectively. The ripple percentage of $V_{c 1}$ is selected to be $5 \%$. Thus capacitor $C_{1}$ can be obtained from (55).

$$
C_{1} \geq \frac{D^{2}}{8(1+k) \omega L f_{s} G_{1}^{2}} \times \frac{V_{c 1}}{V_{c 1, \text { ripple }}}=1473 \mu \mathrm{F}
$$

$C_{1}$ is selected to be $1640 \mu \mathrm{F}$, and $C_{o}$ is chosen to be $1000 \mu \mathrm{F}$.

Some measured results under $V_{r m s}=110 \mathrm{~V}, V_{o}=48 \mathrm{~V}$, and $P_{o}=200 \mathrm{~W}$ are shown in Figs. 6-9. Fig. 6 depicts the waveforms of the input voltage and input current. As can be seen, the input current is in phase with the input voltage. Thus the power factor is almost unity. The waveforms of the coupled-inductor current $i_{L 1}$ and $i_{L 2}$ are shown in Fig. 7. It can be seen that the front-semi stage of the proposed converter is operated in DCM. This is consistent with the operating 


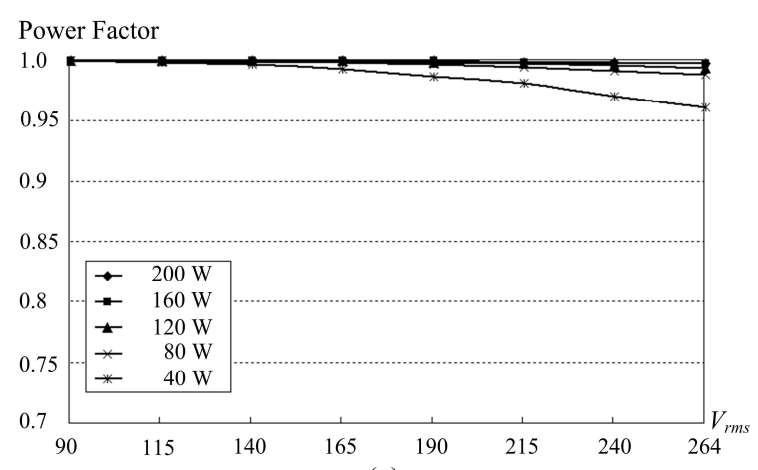

(a)

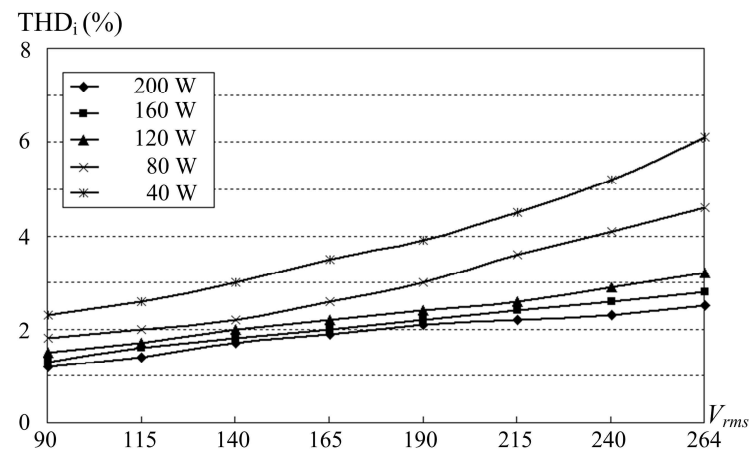

(b)

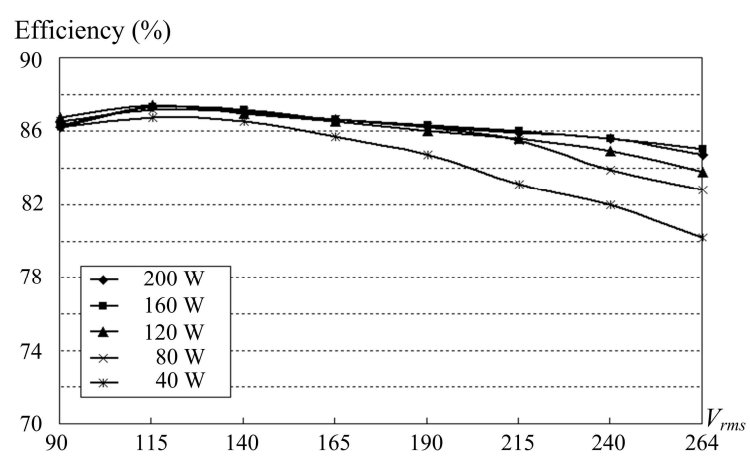

(c)

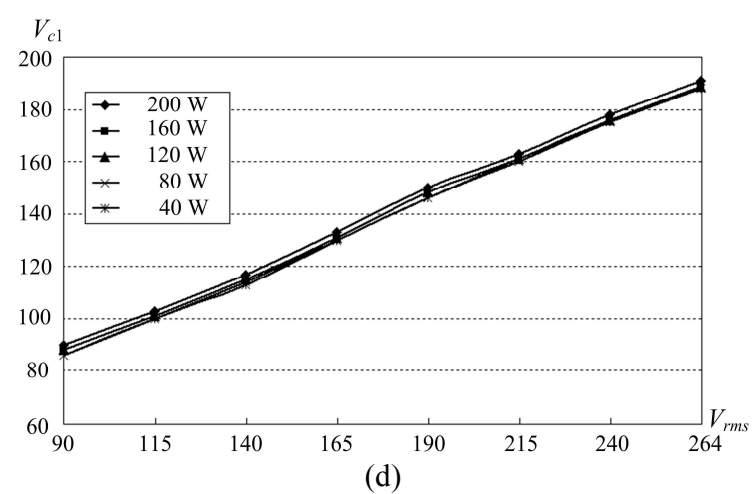

Fig. 10. Measured results under various input voltage and output power, (a) Power factor, (b) $\mathrm{THD}_{\mathrm{i}}$, (c) Efficiency, (d) $V_{c 1}$.

principles. Fig. 8 shows the waveforms of the output-inductor current $i_{L o}$. It can be seen that the rear semi-stage is operated in DCM. This also agrees with the operating principles. The waveforms of output voltage $V_{o}$ and input current $i_{s}$ under load variations between $100 \mathrm{~W}$ and $200 \mathrm{~W}$ are shown in Fig. 9. The output voltage $V_{o}$ is well regulated at $48 \mathrm{~V}$. Moreover, the measured power factor, $\mathrm{THD}_{\mathrm{i}}$, efficiency, and DC-link voltage $V_{c 1}$ under various input voltages and output powers are shown in Fig. 10. From Fig. 10(a), it can be seen that the power factor is higher than 0.96 and that an almost unity power factor is achieved under a heavy load. The $\mathrm{THD}_{\mathrm{i}}$ is less than $6.1 \%$ as shown in Fig. 10(b). Fig. 10(c) shows the measured efficiency. It can be seen that the maximum efficiency is $87.4 \%$. As can be seen in Fig. 10(d), DC-link voltage $V_{c 1}$ is varied with the input voltage and is less than the amplitude of the input voltage. Based on practical applications, the voltage across the capacitor must be less than $450 \mathrm{~V}$. It can be seen that the maximum $V_{c 1}$ is equal to $191 \mathrm{~V}$ at $V_{r m s}=264 \mathrm{~V}$.

\section{CONCLUSIONS}

A new isolated single-phase AC-DC converter is investigated in this paper. A modified AC-DC buck-boost converter and a forward DC-DC converter are integrated in the proposed converter to achieve an almost unity power factor, a low $\mathrm{THD}_{\mathrm{i}}$, a low DC-link voltage, electrical isolation, and an adjustable output voltage. The proposed converter is suitable for universal input voltage and a wide output power range. Moreover, the steady-state analysis of the proposed converter is presented in detail. A prototype circuit of the proposed converter is implemented in the laboratory. From the measured results, it can be seen that a high power factor, a low $\mathrm{THD}_{\mathrm{i}}$, and a low DC-link voltage are achieved under various input voltages and output powers.

\section{ACKNOWLEDGMENT}

The authors gratefully acknowledge financial support from the National Science Council of Taiwan under project NSC 99-2218-E-269-001.

\section{REFERENCES}

[1] J. Zhang, B. Su, and Z. Lu, "Single inductor three-level bridgeless boost power factor correction rectifier with nature voltage clamp," IET Power Electron., Vol. 5, No. 3, pp. 358-365, Mar. 2012.

[2] Y. C. Kimy, L. Jin, J. Lee, and J. Choi, "Direct digital control of single-phase AC/DC PWM converter system," Journal of Power Electronics, Vol. 10, No. 5, pp. 518-527, Sep. 2010.

[3] F. Tahami, S. Poshtkouhi, and H. M. Ahmadian, "Piecewise affine control design for power factor correction rectifiers," Journal of Power Electronics, Vol. 11, No. 3, pp. 327-334, May 2011.

[4] L. Huber, L. Gang, and M. M. Jovanovic, "Design-oriented analysis and performance evaluation of buck PFC front end," IEEE Trans. Power Electron., Vol. 25, No. 1, pp. 85-94, Jan. 2010. 
[5] V. F. Pires and J. F. Silva, "Half-bridge single-phase buck-boost type AC-DC converter with sliding-mode control of the input source current," IEE Electr. Power Appl., Vol. 147, No. 1, pp. 61-67, Jan. 2000.

[6] M. Nagao, "A novel one-stage forward-type power factor correction circuit," IEEE Trans. Power Electron., Vol. 15, No. 1, pp. 103-110, Jan. 2000.

[7] K. I. Hwu and Y. T. Yau, "An interleaved AC-DC converter based on current tracking," IEEE Trans. Ind. Electron., Vol. 56, No. 5, pp. 1456-1463, May 2009.

[8] C. A. Gallo, F. L. Tofoli, and J. A. C. Pinto, "Two-stage isolated switch-mode power supply with high efficiency and high input power factor," IEEE Trans. Ind. Electron., Vol. 57, No. 11, pp. 3754-3766, Nov. 2010.

[9] F. Q. Wang, H. Zhang, and X. K. Ma, "Intermediate-scale instability in two-stage power-factor correction converters," IET Power Electron., Vol. 3, No. 3, pp. 438-445, 2010.

[10] Y. S. Lee and B. T. Lin, "Adding active clamping and soft switching to boost-flyback single-stage isolated power-factor-corrected power supplies," IEEE Trans. Power Electron., Vol. 12, No. 6, pp. 1017-1027, Nov. 1997.

[11] J. B. Kim, N. J. Park, D. Y. Lee, and D. S. Hyun, "A control technique for $120 \mathrm{~Hz}$ DC output ripple-voltage suppression using BIFRED with a small-sized energy storage capacitor," Journal of Power Electronics, Vol. 5, No. 3, pp. 190-197, Jul. 2005.

[12] A. Nasiri, Z. Nie, S. B. Bekiarov, and A. Emadi, "An on-line UPS system with power factor correction and electric isolation using BIFRED converter," IEEE Trans. Ind. Electron., Vol. 55, No. 2, pp. 722-730, Feb. 2008.

[13] H. Y. Li, H. C. Chen, and L. K. Chang, "Analysis and design of a single-stage parallel AC-to-DC converter," IEEE Trans. Power Electron., Vol. 24, No. 12, pp. 2989-3002, Dec. 2009.

[14] J. J. Lee, J. M. Kwon, E. H. Kim, W. Y. Choi, and B. H. Kwon, "Single-stage single-switch PFC flyback converter using a synchronous rectifier," IEEE Trans. Ind. Electron., Vol. 55, No. 3, pp. 1352-1365, Mar. 2008.

[15] D. D. C. Lu, D. K. W. Cheng, and Y. S. Lee, "Analysis of a high-power-factor AC-DC converter with reduced current and voltage stresses," IEE Electr. Power Appl., Vol. 152, No. 4, pp. 943-952, Jul. 2005.

[16] K. T. Kim, W. Y. Choi, J. M. Kwon, and B. H. Kwon, “A single-stage AC/DC converter with low voltage stresses and reduced switching losses," Journal of Power Electronics, Vol. 9, No. 6, pp. 823-834, Nov. 2009.

[17] E. H. Ismail, A. J. Sabzali, and M. A. Al-Saffar, "Buck-boost-type unity power factor rectifier with extended voltage conversion ratio," IEEE Trans. Ind. Electron., Vol. 55, No. 3, pp. 1123-1132, Mar. 2008.
[18] M A. Al-Saffar, E. H. Ismail, and A. J. Sabzali, "Integrated buck-boost-quadratic buck PFC rectifier for universal input applications', IEEE Trans. Power Electron., Vol. 24, No. 12, pp. 2886-2896, Dec. 2009.

[19] T. F. Wu and Y. K. Chen, "Analysis and design of an isolated single-stage converter achieving power-factor correction and fast regulation," IEEE Trans. Ind. Electron., Vol. 46, No. 4, pp. 759-767, Aug. 1999.

[20] J. L. Lin, M. Z. Chang, and S. P. Yang, "Synthesis and analysis for a novel single-stage isolated high power factor correction converter," IEEE Trans. Circuits Syst. I, Reg. Papers, Vol. 52, No. 9, pp. 1928-1939, Sep. 2005.

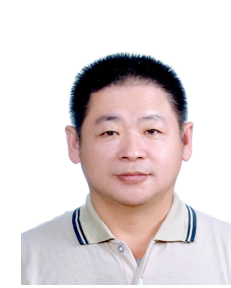

Ming-Rong Lee was born in Pingtung, Taiwan, R.O.C., in 1956. He received his B.S in Electrical Engineering from the National Cheng Kung University, Tainan City, Taiwan, in 1982. He is currently with the Department of Electrical Engineering, Far East University, Tainan City, Taiwan, where he is a Lecturer. His current research interests include power factor correction and dc-dc converters.

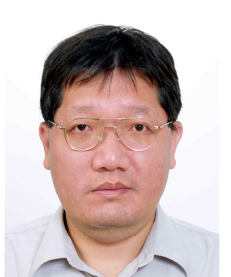

Lung-Sheng Yang was born in Tainan City, Taiwan, R.O.C., in 1967. He received his B.S. in Electrical Engineering from the National Taiwan Institute of Science and Technology, Taipei, Taiwan, in 1990, his M.S. in Electrical Engineering from the National Tsing Hua University, Hsinchu City, Taiwan, in 1992, and his Ph.D. in Electrical Engineering from the National Cheng Kung University, Tainan City, Taiwan, in 2007. He is currently with the Department of Electrical Engineering, Far East University, Tainan City, Taiwan, where he is an Assistant Professor. His current research interests include power factor correction, dc-dc converters, renewable energy conversion, and electronic ballasts.

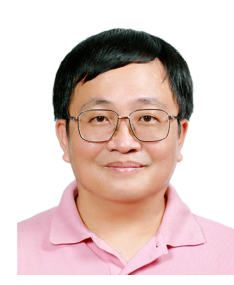

Chia-Ching Lin was born in Kaohsiung, Taiwan, R.O.C., in 1959. He graduated from the Department of Electrical Engineering, Far East University, Tainan City, Taiwan, in 1980. He received his M.S. in Electrical Engineering from the National Cheng Kung University, Tainan City, Taiwan, in 2006. He is currently with the Department of Electrical Engineering, Far East University, Tainan City, Taiwan, where he is an Assistant Professor. His current research interests include power factor correction and dc-dc converters. 